\title{
Redrawing permafrost outreach
}

\author{
Frédéric Bouchard®, Michael Fritz $₫$ and Ylva Sjöberg
}



Permafrost is a fascinating but hidden world of ice, frozen soil, bacteria and gases. The transdisciplinary outreach project Frozen-Ground Cartoons (FGC) makes permafrost science accessible and fun for children, their parents and teachers around the globe.

Occupying more than 20 million $\mathrm{km}^{2}$ across Arctic, Antarctic and mountainous landscapes, permafrost forms a key, yet often overlooked, component of the Earth System. Nearly four million people live in permafrost areas of the Arctic, including Indigenous peoples using these frozen lands for settlement and subsistence hunting and fishing. Like many aspects of the Earth System, permafrost regions are highly sensitive to ongoing anthropogenic activities. Public discussion about science and traditional environmental knowledge is therefore crucial to bring communities together and enhance resilience to the multifaceted consequences of climate warming. Yet, effective illustrations and cross-sector communication and education on the importance of permafrost are often lacking.

The Frozen-Ground Cartoons (FGC) project was born in 2015-2016 with the aim of connecting arts and science along visual, narrative and metaphoric axes. We wanted to make permafrost research accessible and fun, and thereby engage readers and communicate the relevance of the discipline in the global context. With initial funding as an
International Permafrost Association Action Group, two artists from Finland and Canada were recruited to create the cartoons with support from a group of early-career researchers. This 'phase I' culminated in the creation and release of a digital and printed 28-page booklet of comic strips in English. Comic distribution and promotion was channelled through our website, and printed copies sponsored by international research organizations in the home countries of the Action Group's members. Since its launch in 2017, the website has had about 32,500 views from 11,500 visitors and 120 countries, including some with less active permafrost research programmes (for example Italy, India, Brazil and South Africa).

Following from this success, the FGC quickly evolved into a series of by-products and subsequent phases to fulfil user demand. These included: translations into several languages, including Indigenous languages in key permafrost regions such as Greenlandic and Inuktitut; augmented reality material (maps, photos, videos and 3D drawings) accessible via an application developed for smartphones and tablets; and a board game
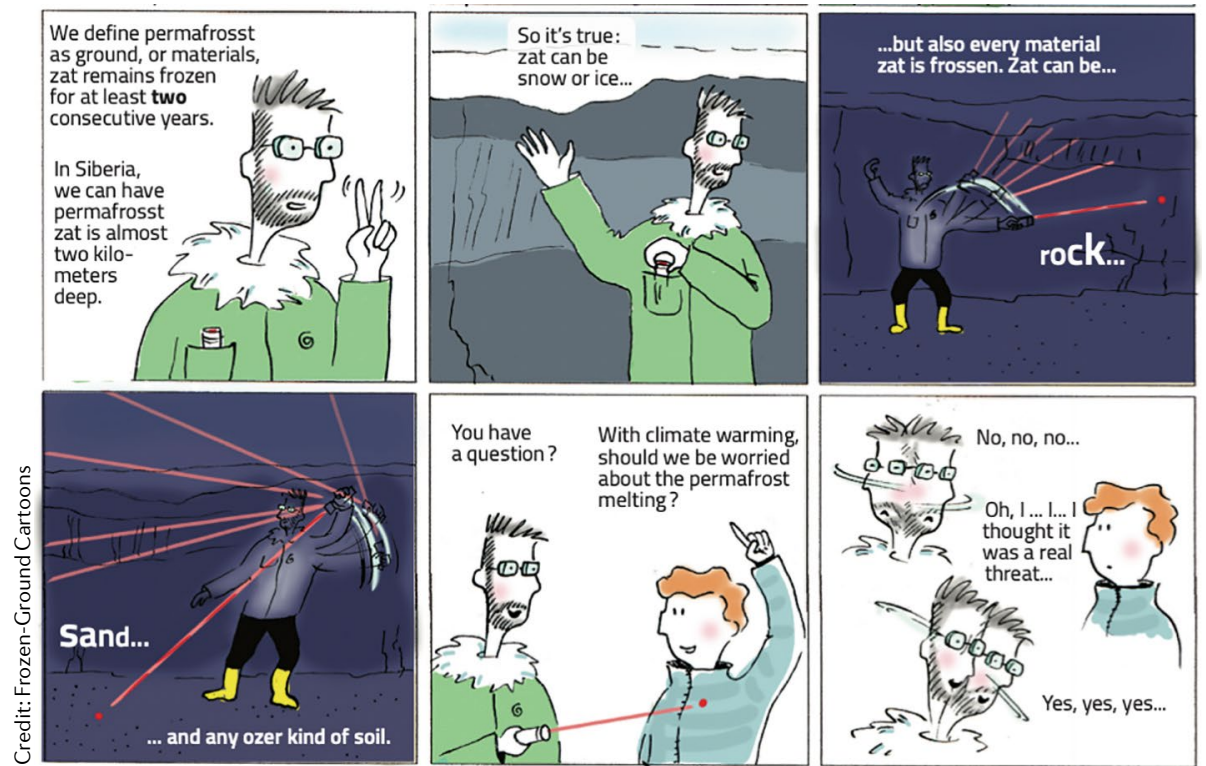

played on a central permafrost world map platform with a series of questions and associated augmented reality material. The board game and augmented reality material form teaching tools that were tested with different groups of high-school students in Luxembourg during permafrost workshops. They were very well received, and the next step is to broaden these permafrost workshops to the whole national high-school curriculum; each teacher would then act as a 'permafrost agent'. We are also now working on a virtual reality project with an illustrator who will merge $3 \mathrm{D}$ cartoons and permafrost science into a story involving school children from California and Yakutia (Siberia).

The success of the FGC project depends on voluntary efforts from more than 50 people, including early-career researchers, offering to translate, promote or share new ideas for creative science outreach. Cartoons offer great advantages for communicating complex scientific concepts by providing visual support and telling captivating stories, and they can be shared easily via social media. The co-production of outreach products by scientists, artists and communicators is a creative process that requires time, but can result in powerful and innovative material for science communication.

Frédéric Bouchard (iD ${ }^{\otimes}$, Michael Fritz (iD ${ }^{2}$ and Ylva Sjöberg ${ }^{3}$

'Department of Applied Geomatics, Université de Sherbrooke, Sherbrooke, Quebec, Canada. ${ }^{2}$ Department of Permafrost Research, Alfred Wegener Institute Helmholtz Centre for Polar and Marine Research, Potsdam, Germany.

${ }^{3}$ Center for Permafrost (CENPERM), Department of Geosciences and Natural Resource Management, University of Copenhagen, Copenhagen, Denmark.

凶e-mail: frederic.bouchard5@usherbrooke.ca https://doi.org/10.1038/s43017-021-00255-8

Competing interests

The authors declare no competing interests.

RELATED LINKS

Action Group: https://ipa.arcticportal.org/activities/

ction-groups

Engage readers: https://doi.org/10.1017/S0032247418000633 Frozen-Ground Cartoons: https://frozengroundcartoon.com 